\title{
General Psychiatry HMGB1 involved in stress-induced depression and its neuroinflammatory priming role: a systematic review
}

\author{
Huifeng Zhang, ${ }^{1}$ Lei Ding, ${ }^{1}$ Ting Shen, ${ }^{2}$ Daihui Peng ${ }^{1}$
}

To cite: Zhang H, Ding L, Shen T, et al. HMGB1 involved in stress-induced depression and its neuroinflammatory priming role: a systematic review. General Psychiatry 2019;32:e100084. doi:10.1136/ gpsych-2019-100084

$\mathrm{HZ}$ and $\mathrm{LD}$ are joint first authors.

Received 06 May 2019

Revised 15 July 2019

Accepted 17 July 2019
Check for updates

(C) Author(s) (or their employer(s)) 2019. Re-use permitted under CC BY-NC. No commercial re-use. See rights and permissions. Published by BMJ.

${ }^{1}$ Division of Mood Disorders, Shanghai Mental Health Center, Shanghai Jiao Tong University School of Medicine, Shanghai, China

${ }^{2}$ Department of Psychiatry, Shanghai Mental Health Center, Shanghai Jiao Tong University School of Medicine, Shanghai, China

Correspondence to Dr Daihui Peng, Division of Mood Disorders, Shanghai Mental Health Center, Shanghai Jiao Tong University School of Medicine, Shanghai, China; pdhsh@126.com

\section{ABSTRACT}

Background Evidence from clinical and preclinical studies has demonstrated that stress can cause depressive-like symptoms including anhedonia and psychomotor retardation, namely, the manifestation of motivational deficits in depression. The proximate mediator of linking social-environmental stress with internal motivational deficits remains elusive, although substantial studies proposed neural endocrine mechanisms. As an endogenous danger-associated molecule, high mobility group box-1 (HMGB1) is necessary and sufficient for stress-induced sensitization of innate immune cells and subsequent (neuro)inflammation.

Aim This review aims to provide evidence to unveil the potential mechanism of the relationship between motivational deficits and stress in depression.

Methods We reviewed original case-control studies investigating the association between HMGB1-mediated inflammation and stress-induced depression. The literature search of Pubmed and Web of Science electronic database from inception up to March 28th, 2019 were conducted by two independent authors. We performed a qualitative systematic review approach to explore the correlation between HMGB1-mediated inflammation and anhedonia/ psychomotor retardation in depression.

Results A total of 69 studies based on search strategy were retrieved and seven eligible studies met the inclusion criteria. Studies showed that HMGB1 was implicated with depressive-like behaviors, which are similar with motivational deficits. Furthermore, HMGB1-mediated inflammation in depressive-like behaviors may be involved in Nod-like receptor family pyrin domain containing three (NLRP3) inflammasome and proinflammatory cytokines, abnormal kynurenine pathway and imbalance between neuroprotective and neurotoxic factors.

Conclusions We found that stress-induced inflammation mediated by HMGB1 may affect motivational deficits through regulating dopamine pathway in corticostriatal neurocircuitry. The systematic review may shed light on the novel neurobiological underpinning for treatment of motivation deficits in depression.

\section{INTRODUCTION}

Major depressive disorder (MDD) is clinically characterised by motivational deficits. ${ }^{1}$ Motivational deficits are manifested in the symptoms of anhedonia and psychomotor retardation. Anhedonia refers to the reduced motivation or ability to experience pleasure, and psychomotor retardation is known as a slowing-down of thought and a reduction of physical movements. ${ }^{2}$ Evidence from clinical and preclinical studies has demonstrated that stress can trigger anhedonia and psychomotor deficits in vulnerable individuals. ${ }^{3}$ Chronic and acute stressors are among the strongest proximal risk factors for MDD. ${ }^{5}$ Consistent with this notion, chronic unpredictable mild stress (CUMS) and social defeat stress have been used to establish animal models of depression, resulting in anhedonia-like behaviours and increasing immobility time.$^{6-8}$ However, few studies directly investigate the impact of stress on brain reward processing and explore the potential mechanisms in stress-induced motivational deficits. Some studies revealed that stress-induced motivational deficits may involve in the abnormal mesolimbic dopaminergic circuit, ${ }^{910}$ although the cause of such dysfunction remains elusive.

During the past decades, substantial evidence has demonstrated that exposure to stress can prime microglia and strengthen the neuroinflammatory response to the central nervous system (CNS) and peripheral inflammatory challenge. ${ }^{11}$ Accordingly, CNS and peripheral inflammation has been assumed to be associated with the psychopathology of MDD. ${ }^{12}$ Therefore, we review clinical and preclinical evidence to clarify the relationship between stress-induced motivational deficits in MDD and the potential signal pathway in the stress-inflammation-mesolimbic reward circuit.

\section{The association between stress and} neuroinflammation: the role of the dangerassociated molecular pattern HMGB1

Psychological and physical stress can potentiate the proinflammatory response of microglia to subsequent immune stimulators through releasing endogenous danger molecules known as danger-associated molecular patterns (DAMPs). ${ }^{11}$ These DAMPs are recognised by pattern recognition receptors 
(PRRs) in the cellular surface, such as toll-like receptors (TLRs) and the receptor for advanced glycation end products (RAGE). CNS and peripheral innate immune system become activated in response to the recognition of DAMPs-PRRs signalling. ${ }^{13}$ However, the proximate DAMPs mediators by which stress primes microglia still need to be elucidated. One previous review showed that several DAMPs, including S100 proteins, high mobility group box-1 (HMGB1), heat shock proteins, ATP and uric acid can result in depressive-like behaviours in stress-induced depression models. ${ }^{14}$ In particular, HMGB1 is considered as master regulator of innate immunity. ${ }^{15}$ Previous studies suggested that HMGB1 signalling is necessary and sufficient for stress-induced sensitisation of microglia, then amplifying the expression of the NLR family pyrin domain containing 3 (NLRP3) inflammasome and proinflammatory cytokines. ${ }^{16}$ Moreover, HMGB1 has been involving in several neuroinflammatory conditions, such as Alzheimer's disease ${ }^{17}$ and brain ischaemia injury. ${ }^{18}$ Therefore, the scope of our review focuses on the HMGB1 as a potential mediator of stress-induced neuroinflammation in MDD.

The association between neuroinflammation and motivational deficits mediated by brain structure and function

Experimental cytokine (eg, injection of typhoid vaccination or LPS) could quickly trigger fatigue, depressed mood, lack of interest and psychomotor retardation in healthy individuals, suggesting the underlying alterations of neural activity in specific regions. Previous studies suggest that stress is implicated with the aetiology of MDD through activating neuroinflammation processes and then involving structural and functional alterations of specific brain regions. ${ }^{19}$ Neuroinflammation exerts direct detrimental effects on brain structure and function by mediating neuronal damage/degeneration, glial activation, mitochondrial dysfunction, demyelination and endothelial damage. ${ }^{20}$ Moreover, these inflammation-induced behavioural changes have been assumed to be associated with the alterations of neurotransmitters metabolism (serotonin, dopamine (DA) and norepinephrine $)^{21} 22$ and the activation of indoleamine 2,3-dioxygenase (IDO) in kynurenine pathway (KP), ${ }^{23}$ which are consistent with the psychopathology of MDD. Neuroimaging techniques have been advanced to confirm the link between inflammation and depression mediated by the alterations in neural regions associated with the regulations of motivation and reward, including prefrontal regions and ventral striatum, ${ }^{24}{ }^{25}$ and the regulation of emotion, including amygdala, anterior cingulate cortex and prefrontal cortex. ${ }^{26} 27$

As mentioned above, evidence has showed that stress can cause depressive-like symptoms including anhedonia and psychomotor retardation, which are common in patients with MDD. ${ }^{28}$ Similar findings were observed in depressive-like animal models by reductions in saccharin preference and increased immobility time. ${ }^{29}$ However, little is known about the underlying mechanism of the relationship between motivational deficits and stress in depression. One candidate neurobiological mechanism, overactive inflammation, was supposed to be associated with motivational deficits in MDD. ${ }^{30}$ Therefore, we hypothesised that stress-induced neuroinflammation mediated by HMGB1 may be implicated with the alterations of corticostriatal reward neurocircuitry contributing to anhedonia and psychomotor retardation in MDD.

\section{METHODS}

\section{Inclusion criteria}

We recruited original studies investigating the association between HMGB1-mediated inflammation and stress-induced depression. Depressive-like behaviour in an animal model was induced by stress, such as CUMS. The studies recruited into this review were case-control studies that compared the expression levels of HMGB1 in stress exposure group and control group. Only studies written in English were recruited into our review.

\section{Exclusion criteria}

Literature reviews, systematic reviews, meta-analysis and conference or meeting abstracts were excluded. Articles where a depressive-like animal model was not induced by stress were also excluded.

\section{Search strategy}

The PubMed and Web of Science electronic databases were searched from inception up to 28 March 2019. The following search string was used: (depression OR major depressive disorder OR unipolar depression OR major depression) AND (HMBG1 OR high-mobility group box 1 protein). Meanwhile, we manually searched the reference lists of each eligible article to identify additional studies.

\section{Data extraction}

For each eligible article, we extracted and recorded the following important information: first author and year of publication, animal models, the changes of expression levels of inflammatory cytokines, depressive-like behaviours and antidepressants-like target.

\section{Data synthesis}

The high level of heterogeneity of HMGB1-mediated inflammatory biomarkers was observed in the present review. Thus, quantitative analysis (eg, meta-analysis) was not conducted. Instead, we performed a qualitative systematic review approach to explore the correlation between HMGB1-mediated inflammation and anhedonia/psychomotor retardation in depression.

\section{RESULTS}

Characteristic of included studies

Our search found 69 studies based on the search strategy and manually checking the reference lists of searched 


\section{9 records identified through database searching (Pubmed n=29; Web of Science $n=40$ )}

49 excluded after reviewing the titles and abstracts (20 duplicates, 29 wrong disease or outcome)

\section{9 articles screened}

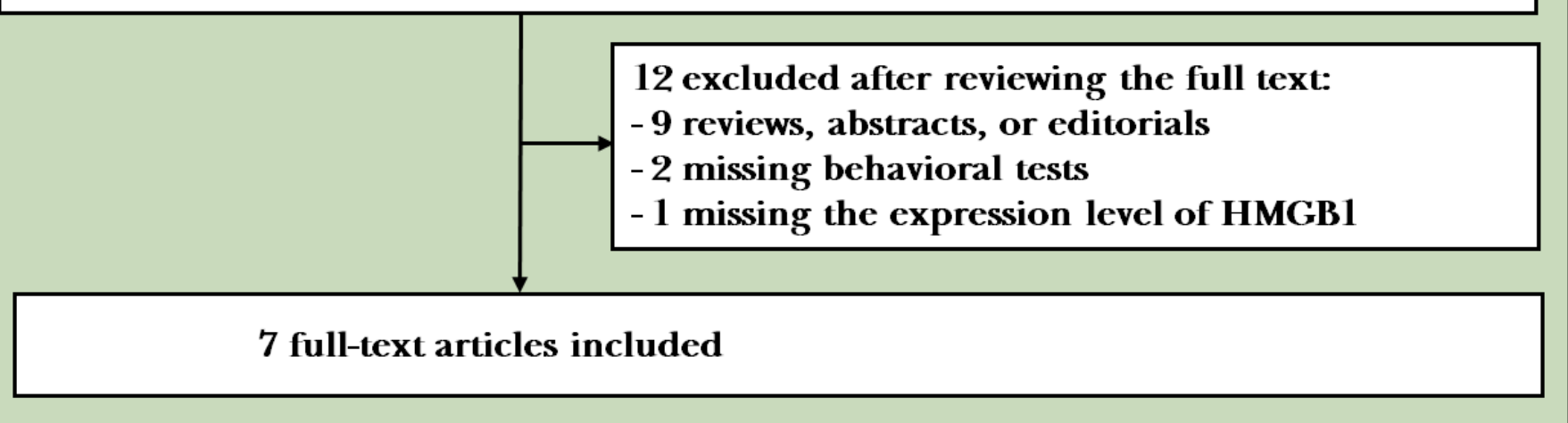

Figure 1 The flowchart of search and study selection.

articles. After title/abstract screening and full text reviewing, only seven eligible studies met the inclusion criteria. The flowchart for search and study selection is illustrated in figure 1. The characteristics of these seven studies are listed in table 1.

\section{Association between HMBG1-mediated inflammation and depression}

All published original research involving HMGB1 in stress-induced depressive animals are listed in table 1. Studies have showed that HMGB1 is implicated with depressive-like behaviours (eg, reduced saccharin preference and reduced locomotor activity), which are similar with motivational deficits (eg, anhedonia and psychomotor retardation) in human studies. HMGB1 elicited anhedonic behaviour via inducing TNF- $\alpha$ and then promoting neuroinflammatory response activation, ${ }^{31}$ whereas glycyrrhizic acid and ethyl pyruvate, inhibitors of HMGB1, could improve depressive-like behaviours. ${ }^{81}$ Moreover, Weber et $a l^{16}$ established inescapable tail shocks animal depressive models to explore whether HMGB1 is a potential mediator of stress-induced microglia priming. ${ }^{16}$ These findings showed that HMGB1 was sufficient to prime microglia and subsequent NLRP3 inflammasome and proinflammatory cytokines. Moreover, HMGB1 mediated depressive behaviour through restraining the activated enzymes in KP, such as IDO. ${ }^{819}$ Noticeably, IDO, the rate-limiting enzyme of $\mathrm{KP}$, is highly inducible by proinflammatory cytokines (eg, TNF- $\alpha$, interleukin $1 \beta$ ). Cheng et $a l^{\beta 2}$ also found that stress-induced depression-like behaviour is mediated by GSK3-dependent TLR4 signalling, which further upregulated HMGB1 and activated nuclear factor $\kappa \mathrm{B}(\mathrm{NF}-\kappa \mathrm{B})$ and NLRP3 inflammasome. ${ }^{32}$ Moreover, persistent microglial HMGB1-RAGE expression increase susceptibility to chronic stress-induced priming of depressive-like behaviours. ${ }^{13}$ Therefore, HMGB1 might be a plausible danger signalling mediator of stress-induced depressive-like behaviours, which is involved in DAMPs pattern recognition, including HMGB1-TLR4 signalling ${ }^{33}$ and HMGB1-RAGE signalling. ${ }^{34}$

\section{DISCUSSION}

In this systematic review, we aimed to explore the association between HMGB1-mediated inflammation and motivation deficits in depression. Numerous preclinical studies strengthen our understanding of the HMGB1-mediated inflammation in depression. Although there is a lack of evidence in clinical studies of HMGB1, evidence from aforementioned reviewed studies indicated that, HMGB1, although not mutually exclusive interpretation, may play a critical role in the regulation of stress-induced neuroinflammation $^{14}$ and be further involved in the motivation dysfunction through altered corticostriatal circuitry. $^{21}$

The association between stress and MDD involving neuroinflammation

Substantial clinical studies have suggested that stress is associated with upregulated inflammatory activity. ${ }^{35} 36$ Consistent with this notion, laboratory-based preclinical studies clarified that acute and chronic stress induced the higher levels of interleukin-6 (IL-6), and C reactive protein in serum and brain tissues, which in turn elicit profound changes of behaviour. ${ }^{37}$ Postmortem studies 
Table 1 Systematic-summarised studies of HMGB1-mediated inflammation in depressive-like animal models

\begin{tabular}{|c|c|c|c|c|}
\hline Study & $\begin{array}{l}\text { Animal } \\
\text { models }\end{array}$ & Biomarkers of inflammation & Behaviours & Antidepressants-like target \\
\hline $\begin{array}{l}\text { Fu et al } \\
(2019)\end{array}$ & CUMS & $\begin{array}{l}\uparrow \text { HMGB, } \uparrow \text { proinflammatory } \\
\text { cytokines (TNF- } \alpha, \text { IL- } 6 \text { and IL-1 } \beta \text { ) }\end{array}$ & $\begin{array}{l}\downarrow \text { Sucrose preference, } \uparrow \text { immobility } \\
\text { time in tail suspension test and } \\
\text { forced swimming test and } \downarrow \text { crossing } \\
\text { numbers in open field test; }\end{array}$ & $\begin{array}{l}\text { Antidepressants-like hesperidin: } \\
\text { inhibited inflammatory processes } \\
\text { through HMGB1/RAGE/NF-אB } \\
\text { signalling pathways }\end{array}$ \\
\hline $\begin{array}{l}\text { Liu et al } \\
\text { (2019) }\end{array}$ & CUMS & $\uparrow$ HMGB, $\uparrow$ TNF- $\alpha$, IL- 6 and IL-1 $\beta$ & $\begin{array}{l}\downarrow \text { Sucrose preference, } \uparrow \text { immobility } \\
\text { time in tail suspension test and } \\
\text { forced swimming test }\end{array}$ & $\begin{array}{l}\text { Antidepressants-like baicalin: } \\
\text { inhibited inflammatory processes } \\
\text { through HMGB1/TLR4/NF-KB } \\
\text { signalling pathways }\end{array}$ \\
\hline $\begin{array}{l}\text { Wang et al } \\
(2018)\end{array}$ & CUMS & $\begin{array}{l}\text { CUMS: } \uparrow \text { Gene expression of } \\
\text { enzymes (IDO, KMO, KYNU) in } \\
\text { KP; HMGB1 inhibitor: prevent the } \\
\text { activated enzymes }\end{array}$ & $\begin{array}{l}\downarrow \text { Sucrose preference, } \uparrow \text { immobility } \\
\text { time in tail suspension test and } \downarrow \\
\text { central distance in open field test }\end{array}$ & $\begin{array}{l}\text { CUMS+HMGB1 inhibitor: prevented } \\
\text { the activated enzymes in KP }\end{array}$ \\
\hline $\begin{array}{l}\text { Lian et al } \\
\text { (2017) }\end{array}$ & CUMS & $\begin{array}{l}\uparrow \text { Serum HMGB1; } \uparrow \text { HMGB1 } \\
\text { expression in cerebral cortex; } \uparrow \\
\text { TNF- } \alpha \text { in hippocampus }\end{array}$ & $\begin{array}{l}\downarrow \text { Sucrose preference and } \uparrow \\
\text { immobility time in tail suspension } \\
\text { test }\end{array}$ & \\
\hline $\begin{array}{l}\text { Frankin et al } \\
(2017)\end{array}$ & CUS & $\begin{array}{l}\uparrow \text { Regulation of HMGB1 } \\
\text { messenger RNA, } \uparrow \text { regulation } \\
\text { of RAGE messenger RNA in } \\
\text { hippocampus microglia }\end{array}$ & $\downarrow$ Sucrose preference & \\
\hline $\begin{array}{l}\text { Cheng et al } \\
\text { (2016) }\end{array}$ & $\begin{array}{l}\text { Inescapable } \\
\text { foot shocks }\end{array}$ & $\begin{array}{l}\uparrow \text { HMGB1 in hippocampus; } \uparrow \\
\text { TNF- } \alpha, \text { IL- } 6, \text { IL-12 and IL-1 } \beta \text { in } \\
\text { hippocampus }\end{array}$ & $\uparrow$ Escape failures & $\begin{array}{l}\text { Involved in GSK3-dependent TLR4 } \\
\text { signalling }\end{array}$ \\
\hline
\end{tabular}

CUMS, chronic unpredictable mild stress; CUS, chronic unpredictable stress; GSK3, glycogen synthase kinase-3; HMGB1, high mobility group box 1; IDO, indoleamine 2,3-dioxygenase; IL-1 $\beta$, interleukin 1 $\beta$; IL-6, interleukin 6; IL-12, interleukin 12; KMO, kynurenine 3-monooxygenase; KP, kynurenine pathway; KYNU, kynurenines; NF- $\mathrm{kB}$, nuclear factor $\mathrm{\kappa B}$; RAGE, receptor for advanced glycation end products; TLR4, toll-like receptor ; TNF- $\alpha$, tumour necrosis factor $\alpha$; rHMGB1, human recombinant HMGB1.

in MDD found that proinflammatory and anti-inflammatory cytokine gene expression were upregulated in the prefrontal cortex..$^{38}$ Neuroimaging studies showed that increased inflammatory response was associated with abnormal corticostriatal reward circuitry in depression, which in turn correlated with increased psychomotor slowing and anhedonia. ${ }^{39}$ Therefore, there is no debate that motivational deficits have been implicated with neuroinflammation in MDD.

The role of the danger-associated molecular pattern HMGB1 in stress-induced motivational deficits

HMGB1 is a chromatin intracellular protein expressed in all tissues of mammals, which mostly locate in nuclei. ${ }^{40} \mathrm{In}$ the peripheral, HMGB1 can be secreted from cells, macrophage and monocytes. In the brain, abundant HMGB1 can be expressed in neurons, microglia and astrocytes. ${ }^{41}$ HMGB1 can be passively released from necrotic cells. In addition, HMGB1 is also involved in active secretion from innate immunes cells in response to stress. ${ }^{31}$ It has emerged as one of the main mediators in the pathophysiology of autoimmune diseases and neuroinflammation, ${ }^{42}$ such as systemic lupus erythematosus, cerebral ischaemia, traumatic brain injury and seizure. The extracellular HMGB1 is an endogenous danger and priming signal that uses cellular-ligand PRRs, including TLR2,
TLR4 and RAGE. ${ }^{14}$ Activation of PRRs can initiate cell proliferation and migration as well as proinflammatory cytokine synthesis through mitogen-activated protein kinases-NF- $\mathrm{KB}$ signalling pathway. ${ }^{43}$ Moreover, stress-induced neuroinflammation contribute to vulnerability to depression that involves upregulation of HMGB1, activated NF-KB and subsequent exaggerated NLRP3 inflammasome. ${ }^{32}{ }^{44}$ The mechanism of HMGB1 under oxidative stress in depression was supported by the finding that redox forms of HMGB1, but not nonoxid-HMGB1, induced depressive-like behaviour mainly through neuroinflammatory response activation. ${ }^{45}$ As mentioned in table 1, HMGB1-mediated inflammation could induce depressive-like behaviours in animal models, such as decreased sucrose preference and increased immobility time in the tail suspension test and forced swimming test. Of note, these behaviours are similar to anhedonia and psychomotor retardations in depressed subjects, namely, the manifestation of motivational deficits.

Neurobiological basis of inflammation-induced motivational deficits in MDD: dopamine and corticostriatal neurocircuitry Symptoms related to motivational deficits are difficult to treat by selective serotonin reuptake inhibitors and serotonin and norepinephrine reuptake inhibitors, ${ }^{46}$ indicating that other neurotransmitters may be implicated 
Table 2 Summary of findings from neuroimaging studies exploring the effect of inflammation on glutamate/dopamine and/or reward circuitry

\begin{tabular}{|c|c|c|c|}
\hline Study & $\begin{array}{l}\text { Neuroimaging } \\
\text { technique }\end{array}$ & Participants & Findings \\
\hline $\begin{array}{l}\text { Slavich et al } \\
\text { (2010) }\end{array}$ & $\mathrm{fMRI}$ & 31 healthy subjects & $\begin{array}{l}\text { Exposure to the laboratory-based social stressor: sTNF } \alpha \mathrm{RII} \uparrow \propto \uparrow \text { dorsal anterior } \\
\text { cingulate cortex and anterior insula activity }\end{array}$ \\
\hline $\begin{array}{l}\text { Haroon et al } \\
(2016)\end{array}$ & MRS,CSI & $\begin{array}{l}50 \text { medication-free } \\
\text { MDD }\end{array}$ & $\begin{array}{l}\text { log plasma CRP } \uparrow \propto l o g \text { left basal ganglia glutamate } \uparrow \text {; log left basal ganglia glutamate } \\
\propto \text { anhedonia and psychomotor slowing; plasma and CSF CRP } \propto \text { CSI measures of } \\
\text { basal ganglia glutamate and the glial marker myoinositol }\end{array}$ \\
\hline $\begin{array}{l}\text { Felger et al } \\
(2016)\end{array}$ & $\mathrm{fMRI}$ & $\begin{array}{l}48 \text { medication-free } \\
\text { MDD }\end{array}$ & $\begin{array}{l}\text { CRP } \uparrow \propto \downarrow \text { connectivity between ventral striatum and vmPFC, which in turn correlated } \\
\text { with anhedonia } \uparrow \text {; CRP } \uparrow \propto \downarrow \text { dorsal striatal to vmPFC and presupplementary motor area } \\
\text { connectivity, which correlated with } \uparrow \text { motor speed and } \downarrow \text { psychomotor slowing }\end{array}$ \\
\hline $\begin{array}{l}\text { Lapidus et al } \\
\text { (2014) }\end{array}$ & ${ }^{1} \mathrm{H}$ MRS & $17 \mathrm{MDD}$ vs $17 \mathrm{HC}$ & $\begin{array}{l}\text { Anhedonia severity } \propto \downarrow \text { occipital GSH levels, which indirectly reflect oxidative stress in } \\
\text { neuroinflammation }\end{array}$ \\
\hline $\begin{array}{l}\text { Dowell et al } \\
\text { (2016) }\end{array}$ & qMTI & $\begin{array}{l}23 \text { patients with } \\
\text { hepatitis C }\end{array}$ & $\begin{array}{l}\text { After IFN- } \alpha \text { injection: inflammation-induced acute change in striatal microstructure } \\
\text { predicted development of fatigue but not mood symptoms }\end{array}$ \\
\hline $\begin{array}{l}\text { Capuron et al } \\
(2012)\end{array}$ & $\begin{array}{l}{ }^{18} \mathrm{~F} \text {-dopa PET } \\
\text { fMRI }\end{array}$ & $\begin{array}{l}28 \text { patients with } \\
\text { hepatitis C }\end{array}$ & $\begin{array}{l}\text { Cross-sectional studies: after IFN- } \alpha \text { treatment, inflammation-induced activation of the } \\
\text { ventral striatum } \downarrow \propto \text { anhedonia and fatigue } \\
\text { Longitudinal studies: } \uparrow{ }^{18} \mathrm{~F} \text {-dopa uptake and } \downarrow^{18} \mathrm{~F} \text {-dopa turnover in caudate, putamen } \\
\text { and ventral striatum; baseline and percentage change in }{ }^{18} \mathrm{~F} \text {-dopa uptake and turnover } \\
\propto \text { depression, fatigue and neurotoxicity }\end{array}$ \\
\hline $\begin{array}{l}\text { Swarz et al } \\
(2017)\end{array}$ & fMRI & $\begin{array}{l}448 \text { healthy } \\
\text { subjects }\end{array}$ & $\begin{array}{l}\text { IL- } 18 \text { risk haplotype } \propto \text { anhedonia in women through } \uparrow \text { threat-related amygdala } \\
\text { reactivity }\end{array}$ \\
\hline
\end{tabular}

$\propto$ : significant correlation; $\uparrow$ : increased; $\downarrow$ : decreased.

CRP, C reactive protein; CSF, cerebrospinal fluid; CSI, chemical shift imaging; HC, healthy controls; $1 \mathrm{H}$ MRS, proton MRS; IL-6, interleukin 6 ; IL-18, interleukin 18; MDD, major depressive disorder; MRS, magnetic resonance spectroscopy; PET, positron emission tomography; dmPFC, dorsomedial prefrontal cortex; fMRI, functional MRI; qMTI, quantitative magnetisation transfer imaging; qMTI, quantitative magnetisation transfer imaging; sTNF $\alpha$ RII, a soluble receptor for tumour necrosis factor- $\alpha$; subACC, subgenera region of the anterior cingulate cortex.

with inflammation-induced motivational deficits in MDD. ${ }^{47}$ Experimental studies in rats found that lesions of dopaminergic neurons in the mesolimbic system could cause anhedonic behaviours. ${ }^{48}$ In humans, similar findings have been observed that blocking DA reuptake or/ and increasing DA release can improve motivational activity. ${ }^{49}$ Hence, substantial evidence demonstrated that DA dysfunction may contribute to the regulation of motivational deficits in depression. ${ }^{21}$ Consistent with this, neuroimaging and pharmacological studies found that dopaminergic transmission could enhance striatal activation and corticostriatal functional connectivity in depressive subjects. ${ }^{51}$

Given that dopaminergic neurons of the mesolimbic system involved in motivation and reward-behaviours, numerous neuroimaging studies have found a significant relationship between motivational deficits and the mesolimbic reward circuit, including prefrontal regions, ventral striatum, afferent and efferent projections (see table 2). Functional MRI studies revealed that decreased ventral striatum response and disturbance of orbitofrontal cortex were associated with anhedonia and fatigue mediated by inflammatory cytokines. ${ }^{39} 52$ Moreover, prefrontal cortex overactivity suppressed reward-motivated behaviours by modulating striatal activity ${ }^{53}$ Positron emission tomography studies using the $\mathrm{D}_{2 / 3}$ receptor-selective radiotracer $\left[{ }^{11} \mathrm{C}\right]$ raclopride found that depressed subjects showed increased $\mathrm{D}_{2 / 3}$ receptor availability in the ventral striatum. ${ }^{54}$ As such, neuroimaging studies have provided some robust evidence that corticostriatal reward circuit has been involved in motivational deficits in depression. ${ }^{25}$

\section{Candidate mechanisms of stress-induced neuroinflammation} effects on motivational deficits through dopaminergic corticostriatal neurocircuitry

Exposure to stress can eventually result in a continuum of clinical manifestations, including anhedonia and psychomotor retardation. However, little is known about the potential mechanisms of the relationship between stress-induced neuroinflammation effects on motivational deficits in depression. Based on aforementioned studies, the relatively reliable notion can be drawn that HMGB1-mediated neuroinflammation may be involved in motivational deficits in depression. Several candidate mechanisms have been proposed, including regulating the synthesis, transportation and availability of DA, KP pathway modulating the expression level of glutamate, abnormal synaptic plasticity and neuronal dysfunction. 


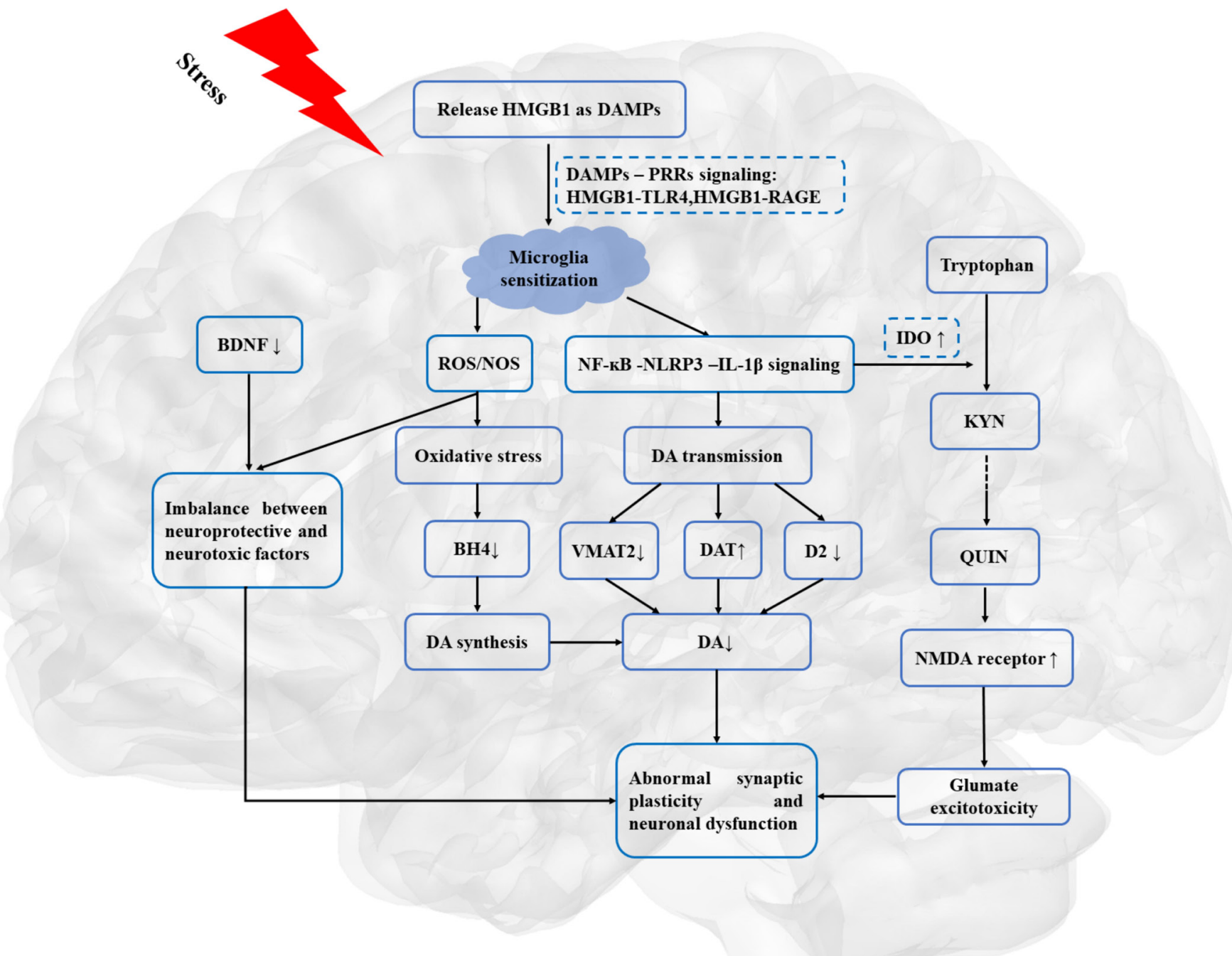

Figure 2 HMGB1, as a priming signalling, involved in the stress-neuroinflammation-mesolimbic dopaminergic pathway. BDNF, brain-derived neurotrophic factor; DA, dopamine; DAMPs, danger-associated molecular patterns; DAT, dopamine transporters; D2, dopamine receptor 2; HMGB1, high mobility group box 1; IL-1 $\beta$, interleukin 1 $\beta$; IDO, indoleamine 2,3 dioxygenase; KYN, kynurenine; NMDA, N-methyl-d-aspartate; NF- $\mathrm{B}$, nuclear factor $\kappa \mathrm{B}$; NOS, nitrogen species; PRRs, pattern recognition receptors; QUIN, quinolinic acid; RAGE, receptor for advanced glycation end products; ROS, reactive oxygen species; TLR4, toll-like receptor 4; VMAT-2, vesicular monoamine transporter-2.

More specifically, growing evidence has demonstrated that HMGB1-mediated neuroinflammation exerts on the synthesis, transportation and availability of DA. After exposure to stress, microglia secreted reactive oxygen species (ROS) and nitrogen species (NOS), which may rapidly decrease neopterin and tetrahydrobiopterin (BH4) availability, resulting in inactivation of phenylalanine hydroxylase (PAH) and tyrosine hydroxylase $(\mathrm{TH}){ }^{55}$ As rate-limiting enzymes for DA synthesis, $\mathrm{PAH}$ and $\mathrm{TH}$ can catalyse phenylalanine into tyrosine and then gradually convert to DA. As such, DA synthesis is hampered by HMGB1-mediated inflammation via increasing oxidative stress. Moreover, further evidence reveals that HMGB1-mediated inflammation also affects the transportation and availability of DA. Given that vesicular monoamine transporter-2 (VMAT-2) exerts on the transportation of synaptic DA, biomarkers of inflammation may affect the release of synaptic DA by regulating the expression and function of VMAT-2. Consistent with this notion, proinflammatory cytokines can decrease expression of VMAT-2 in experimental studies. ${ }^{56}$ Hence, biomarkers of inflammation may also decrease DA signalling by reducing D2 receptor and increasing DA transporter (DAT).$^{21}$ Consequently, HMGB1-mediated inflammation may interrupt the metabolism of DA, which can be supposed to impair the function of corticostriatal neurocircuitry and to result in motivational deficits.

Another mediator about regulation of DA function and corticostriatal neurocircuitry is glutamate. Magnetic resonance spectroscopy studies suggested that inflammatory cytokines may cause the increased concentrations of glutamate in the basal ganglia, which in turn associated with psychomotor slowing and anhedonia in patients with MDD ${ }^{57}$ Furthermore, glutamate receptor antagonist 
ketamine could improve depressive symptoms in human and laboratory animal studies. One pathway by which glutamate neurotransmission involves in HMGB1-mediated motivational deficits may be indirectly mediated by KP rate-limiting enzymes and neurotoxic metabolites. Consistent with this, IDO inhibitor 1-mehtyltryptophan could attenuate anhedonia-like behaviour in an animal model. ${ }^{58}$ In human studies, an index of IDO activity (kynurenine/tryptophan) was associated with the severity of anhedonia in depressed subjects. ${ }^{59}$ Proinflammatory cytokines (eg, interferon- $\alpha$, TNF and IL- 6 ) upregulate the expression of vital enzymes (eg, IDO, kynurenine-3-monooxygenase) involved in the neurotoxic arm of the KP. As such, under the catalysis of immune-mediated activation of IDO and kynurenine-3-monooxygenase, tryptophan is converted to neurotoxic metabolites 3-hydroxykynurenine, 3-hydroxyanthranilic acid and quinolinic acid (QUIN) ${ }^{60}$ Particularly, increasing neurotoxic metabolite QUIN can heighten the activity of N-methyl-d-aspartate glutamatergic receptor and alter the glutamatergic neurotransmission, which subsequently causes glutamate excitotoxicity in the brain. Alternatively, another pathway is that HMGB1-mediated inflammation directly results in the increasing extracellular glutamate buildup. ${ }^{61}$ As mentioned above, microglia secreted ROS and NOS resulting in the increasing oxidative stress in the brain. ${ }^{55}$ The imbalance between neuroprotective factors and neurotoxic factors causes the dysfunction of glutamate exchange in cell membranes, which further increases the concentration of extracellular glutamate and the synthesis of DA. Thus, excessive glutamate neurotransmission and excitotoxicity may be involved in the pathophysiological progression of HMGB1-mediated motivational deficits in MDD. $^{62}$

Moreover, another plausible mechanism of HMGB1-mediated motivational deficits involves abnormal synaptic plasticity and neuronal dysfunction. Therefore, dysfunction of DA in corticostriatal neurocircuitry may cause abnormal corticostriatal synaptic connections. Evidence from animal studies showed that chronic stress caused front striatal reorganisation including neuronal densities, number of intersections and dendrites morphology, which caused a bias in behaviours. ${ }^{63}$ Furthermore, LPS-induced inflammation-related depression was implicated in the alteration of brain-derived neurotrophic factor (BDNF) and its receptor, tropomycin receptor kinase B (TrkB) in frontostriatal regions. ${ }^{64}$ As a neurotrophic protein, BDNF plays a vital role in maintaining the survival of existing neurons and enhancing the growth and differentiation of new neurons and synapses. As mentioned above, HMGB1-mediated inflammation produces neurotoxic metabolites (eg, ROS, proinflammatory factors). Hence, excessive neurotoxic metabolites and abnormal BDNFTrkB signalling may cause neuronal degeneration and alteration of synaptic plasticity in frontostriatal neurocircuitry, which in turn affect reward-related behaviours.

As illustrated in figure 2, HMGB1-mediated inflammation may lead to the dysfunction of DA neurotransmission and dopaminergic corticostriatal circuitry, which may provide the neurobiological basis for reduction in motivation in depression.

\section{DISCUSSION}

This systematic review indicated that HMGB1 may shed light on the stress-neuroinflammation-mesolimbic dopaminergic pathway in the understanding of the pathopsychological mechanism underlying depressive behaviours, such as anhedonia and psychomotor retardation. The importance of HMGB1-mediated inflammation in depression may need to be stated explicitly, with a discussion of the potential implications for the understanding of the pathopsychology of MDD.

Contributors DHP, TS, and HFZ designed the protocol and searched the literature. HFZ and LD screened the studies and extracted the data. TS double-checked the extracted studies. HFZ wrote the first draft of the manuscript. DHP and TS have revised the main manuscript. All authors have approved the final version of the main manuscript for submission.

Funding This research was supported by the National Key Research and Development Program (Grant No. 2016YFC0906400) and Shanghai Science and Technology Committee (Grant No. 18JC1420304).

Competing interests None declared.

Patient consent for publication Not required.

Provenance and peer review Not commissioned; externally peer reviewed.

Data availability statement All the relevant data has been presented in Tables and Figures. No additional data are available.

Open access This is an open access article distributed in accordance with the Creative Commons Attribution Non Commercial (CC BY-NC 4.0) license, which permits others to distribute, remix, adapt, build upon this work non-commercially, and license their derivative works on different terms, provided the original work is properly cited, appropriate credit is given, any changes made indicated, and the use is non-commercial. See: http://creativecommons.org/licenses/by-nc/4.0/.

\section{REFERENCES}

1 Belmaker RH, Agam G. Major depressive disorder. N Engl J Med Overseas Ed 2008;358:55-68.

2 Treadway MT, Zald DH. Parsing anhedonia: translational models of Reward-Processing deficits in psychopathology. Curr Dir Psychol Sci 2013;22:244-9.

3 Der-Avakian A, Mazei-Robison MS, Kesby JP, et al. Enduring deficits in brain reward function after chronic social defeat in rats: susceptibility, resilience, and antidepressant response. Biol Psychiatry 2014;76:542-9.

4 Wood SK, Bhatnagar S. Resilience to the effects of social stress: evidence from clinical and preclinical studies on the role of coping strategies. Neurobiol Stress 2015;1:164-73.

5 Malykhin NV, Coupland NJ. Hippocampal neuroplasticity in major depressive disorder. Neuroscience 2015;309:200-13.

6 Huang G-B, Zhao T, Gao X-L, et al. Effect of chronic social defeat stress on behaviors and dopamine receptor in adult mice. Prog Neuropsychopharmacol Biol Psychiatry 2016;66:73-9.

7 Jin H-M, Shrestha Muna S, Bagalkot TR, et al. The effects of social defeat on behavior and dopaminergic markers in mice. Neuroscience 2015;288:167-77.

8 Wang B. Hmgb1 mediates depressive behavior induced by chronic stress through activating the kynurenine pathway. Brain Behav Immun 2017.

9 Chaudhury D, Walsh JJ, Friedman AK, et al. Rapid regulation of depression-related behaviours by control of midbrain dopamine neurons. Nature 2013;493:532-6.

10 Krishnan V, Han M-H, Graham DL, et al. Molecular adaptations underlying susceptibility and resistance to social defeat in brain reward regions. Cell 2007;131:391-404. 
11 Frank MG, Weber MD, Watkins LR, et al. Stress sounds the alarmin: the role of the danger-associated molecular pattern HMGB1 in stress-induced neuroinflammatory priming. Brain Behav Immun 2015:48:1-7.

12 Byrne ML, Whittle S, Allen NB. The role of brain structure and function in the association between inflammation and depressive symptoms. Psychosom Med 2016;78:389-400.

13 Franklin TC, Wohleb ES, Zhang Y, et al. Persistent increase in microglial RAGE contributes to chronic stress-induced priming of depressive-like behavior. Biol Psychiatry 2018;83:50-60.

14 Franklin TC, Xu C, Duman RS. Depression and sterile inflammation: essential role of danger associated molecular patterns. Brain Behav Immun 2017.

15 Castiglioni A, Canti V, Rovere-Querini P, et al. High-mobility group box 1 (HMGB1) as a master regulator of innate immunity. Cell Tissue Res 2011;343:189-99.

16 Weber MD, Frank MG, Tracey KJ, et al. Stress induces the dangerassociated molecular pattern HMGB-1 in the hippocampus of male Sprague Dawley rats: a priming stimulus of microglia and the NLRP3 inflammasome. J Neurosci 2015;35:316-24.

17 Festoff BW, Sajja RK, van Dreden P, et al. Hmgb1 and thrombin mediate the blood-brain barrier dysfunction acting as biomarkers of neuroinflammation and progression to neurodegeneration in Alzheimer's disease. J Neuroinflammation 2016;13:194.

18 Zhang J, Takahashi HK, Liu K, et al. Anti-high mobility group box-1 monoclonal antibody protects the blood-brain barrier from ischemiainduced disruption in rats. Stroke 2011;42:1420-8.

19 Beumer W, Gibney SM, Drexhage RC, et al. The immune theory of psychiatric diseases: a key role for activated microglia and circulating monocytes. J Leukoc Biol 2012;92): :959-75.

20 Sankowski R, Mader S, Valdés-Ferrer SI. Systemic inflammation and the brain: novel roles of genetic, molecular, and environmental cues as drivers of neurodegeneration. Front Cell Neurosci 2015;9(Suppl 5):28.

21 Felger JC, Treadway MT. Inflammation effects on motivation and motor activity: role of dopamine. Neuropsychopharmacology 2017;42:216-41.

22 Shah D, Blockx I, Keliris GA, et al. Cholinergic and serotonergic modulations differentially affect large-scale functional networks in the mouse brain. Brain Struct Funct 2016;221:3067-79.

23 Steiner J, Walter M, Gos T, et al. Severe depression is associated with increased microglial quinolinic acid in subregions of the anterior cingulate gyrus: evidence for an immune-modulated glutamatergic neurotransmission? J Neuroinflammation 2011;8:94.

24 Zhang W-N, Chang S-H, Guo L-Y, et al. The neural correlates of reward-related processing in major depressive disorder: a metaanalysis of functional magnetic resonance imaging studies. $J$ Affect Disord 2013;151:531-9.

25 Der-Avakian A, Markou A. The neurobiology of anhedonia and other reward-related deficits. Trends Neurosci 2012;35:68-77.

26 Muscatell KA, Dedovic K, Slavich GM, et al. Greater amygdala activity and dorsomedial prefrontal-amygdala coupling are associated with enhanced inflammatory responses to stress. Brain Behav Immun 2015;43:46-53.

27 Moshkin MP, Akulov AE, Petrovski DV, et al. Proton magnetic resonance spectroscopy of brain metabolic shifts induced by acute administration of 2-deoxy-D-glucose and lipopolysaccharides. NMR Biomed 2014;27:399-405.

28 Haroon E, Woolwine BJ, Chen X, et al. IFN-alpha-induced cortical and subcortical glutamate changes assessed by magnetic resonance spectroscopy. Neuropsychopharmacology 2014;39:1777-85.

29 Nunes EJ, Randall PA, Estrada A, et al. Effort-related motivational effects of the pro-inflammatory cytokine interleukin 1-beta: studies with the concurrent fixed ratio 5/ Chow feeding choice task. Psychopharmacology 2014;231:727-36.

30 Simpson EH, Balsam PD. Behavioral neuroscience of motivation. Springer International Publishing, 2016.

31 Wu T-Y, Liu L, Zhang W, et al. High-Mobility group box-1 was released actively and involved in LPS induced depressive-like behavior. J Psychiatr Res 2015;64:99-106.

32 Cheng Y, Pardo M, Armini RdeS, et al. Stress-Induced neuroinflammation is mediated by GSK3-dependent TLR4 signaling that promotes susceptibility to depression-like behavior. Brain Behav Immun 2016;53:207-22.

33 Liu L, Dong Y, Shan X, et al. Anti-Depressive effectiveness of baicalin in vitro and in vivo. Molecules 2019;24.

34 Fu H, Liu L, Tong Y, et al. The antidepressant effects of hesperidin on chronic unpredictable mild stress-induced mice. Eur J Pharmacol 2019;853:236-46.
35 Slopen N, Kubzansky LD, McLaughlin KA, et al. Childhood adversity and inflammatory processes in youth: a prospective study. Psychoneuroendocrinology 2013;38:188-200.

36 Danese A, Pariante CM, Caspi A, et al. Childhood maltreatment predicts adult inflammation in a life-course study. Proc Natl Acad Sci U S A 2007;104:1319-24.

37 Pan Y, Chen X-Y, Zhang Q-Y, et al. Microglial NLRP3 inflammasome activation mediates IL-1 $\beta$-related inflammation in prefrontal cortex of depressive rats. Brain Behav Immun 2014;41:90-100.

38 Shelton RC, Claiborne J, Sidoryk-Wegrzynowicz M, et al. Altered expression of genes involved in inflammation and apoptosis in frontal cortex in major depression. Mol Psychiatry 2011;16:751-62.

39 Felger JC, Li Z, Haroon E, et al. Inflammation is associated with decreased functional connectivity within corticostriatal reward circuitry in depression. Mol Psychiatry 2016;21:1358-65.

40 Fang P, Schachner M, Shen Y-Q. Hmgb1 in development and diseases of the central nervous system. Mol Neurobiol 2012;45:499-506.

41 Palumbo R, Sampaolesi M, De Marchis F, et al. Extracellular HMGB1, a signal of tissue damage, induces mesoangioblast migration and proliferation. J Cell Biol 2004;164:441-9.

42 Venereau E. Hmgb1 as biomarker and drug target, 2016: 534-44.

43 Yang $\mathrm{H}$, Wang $\mathrm{H}$, Czura CJ, et al. The cytokine activity of HMGB1. J Leukoc Biol 2005;78:1-8.

44 Wang Bet al. Glycyrrhizic acid ameliorates the kynurenine pathway in association with its antidepressant effect. Behav Brain Res 2018.

45 Lian Y-J, Gong H, Wu T-Y, et al. Ds-HMGB1 and fr-HMGB induce depressive behavior through neuroinflammation in contrast to nonoxid-HMGB1. Brain Behav Immun 2017;59: :322-32.

46 Targum SD. M.J.I.i.c.n. fava, fatigue as a residual symptom of depression, 2011.

47 Nutt D, Demyttenaere K, Janka Z, et al. The other face of depression, reduced positive affect: the role of catecholamines in causation and cure. J Psychopharmacol 2007;21:461-71.

48 Winter C, von Rumohr A, Mundt A, et al. Lesions of dopaminergic neurons in the substantia nigra pars compacta and in the ventral tegmental area enhance depressive-like behavior in rats. Behav Brain Res 2007;184:133-41.

49 Yohn SE, Errante EE, Rosenbloom-Snow A, et al. Blockade of uptake for dopamine, but not norepinephrine or $5-\mathrm{HT}$, increases selection of high effort instrumental activity: implications for treatment of effort-related motivational symptoms in psychopathology. Neuropharmacology 2016;109:270-80.

50 Randall PA, Lee CA, Podurgiel SJ, et al. Bupropion increases selection of high effort activity in rats tested on a progressive ratio/ chow feeding choice procedure: implications for treatment of effort-related motivational symptoms. Int J Neuropsychopharmacol 2015;18.

51 Admon R, Kaiser RH, Dillon DG, et al. Dopaminergic enhancement of striatal response to reward in major depression. Am J Psychiatry 2017;174:378-86.

52 Capuron L, Pagnoni G, Drake DF, et al. Dopaminergic mechanisms of reduced basal ganglia responses to hedonic reward during interferon alfa administration. Arch Gen Psychiatry 2012;69:1044-53.

53 Ferenczi EA, Zalocusky KA, Liston C, et al. Prefrontal cortical regulation of brainwide circuit dynamics and reward-related behavior. Science 2016;351:aac9698.

54 Peciña M, Sikora M, Avery ET, et al. Striatal dopamine D2/3 receptor-mediated neurotransmission in major depression: implications for anhedonia, anxiety and treatment response. Eur Neuropsychopharmacol 2017;27:977-86.

55 Haroon E, Miller AH. Inflammation effects on brain glutamate in depression: mechanistic considerations and treatment implications. Curr Top Behav Neurosci 2016;31:173-98.

56 Kazumori H, Ishihara S, Rumi MAK, et al. Transforming growth factor-alpha directly augments histidine decarboxylase and vesicular monoamine transporter 2 production in rat enterochromaffin-like cells. Am J Physiol Gastrointest Liver Physiol 2004;286:G508-G514

57 Haroon E, Fleischer CC, Felger JC, et al. Conceptual convergence: increased inflammation is associated with increased basal ganglia glutamate in patients with major depression. Mol Psychiatry 2016;21:1351-7.

58 Salazar A, Gonzalez-Rivera BL, Redus L, et al. Indoleamine 2,3-dioxygenase mediates anhedonia and anxiety-like behaviors caused by peripheral lipopolysaccharide immune challenge. Horm Behav 2012;62:202-9.

59 Gabbay V, Ely BA, Babb J, et al. The possible role of the kynurenine pathway in anhedonia in adolescents. J Neural Transm 2012;119:253-60. 
60 Zunszain PA, Anacker C, Cattaneo A, et al. Interleukin-1ß: a new regulator of the kynurenine pathway affecting human hippocampal neurogenesis. Neuropsychopharmacology 2012;37:939-49.

61 Pedrazzi M, Raiteri L, Bonanno G, et al. Stimulation of excitatory amino acid release from adult mouse brain glia subcellular particles by high mobility group box 1 protein. $J$ Neurochem 2006;99:827-38.

62 Bay-Richter C, Linderholm KR, Lim CK, et al. A role for inflammatory metabolites as modulators of the glutamate $\mathrm{N}$-methyl-D-aspartate receptor in depression and suicidality. Brain Behav Immun 2015;43:110-7.

63 Dias-Ferreira E, Sousa JC, Melo I, et al. Chronic stress causes frontostriatal reorganization and affects decision-making. Science 2009;325:621-5.

64 Sharma A, Hashimoto K. Brain-derived neurotrophic factor (BDNF) - TrkB signaling in inflammation-related depression and potential therapeutic targets. Current Neuropharmacology 2016;14.

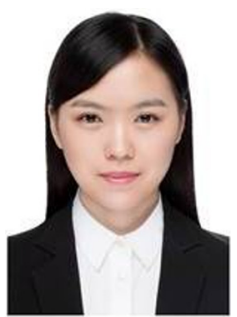

Huifeng Zhang graduated with a bachelor's degree from Xinhua Hospital affiliated to Shanghai Jiao Tong University, school of medicine in 2017. She is currently studying for a master's degree at the Shanghai Mental Health Center, Shanghai Jiao Tong University school of medicine, Shanghai, China. Her research interest includes major depressive disorder and bipolar disorder. 